\title{
Constitutive nitric oxide synthase is associated with retinal vascular permeability in early diabetic rats
}

\author{
M.Takeda ${ }^{2}$, F.Mori ${ }^{2}$, A. Yoshida ${ }^{2}$, A.Takamiya ${ }^{2}$, S. Nakagomi ${ }^{1}$, E. Sato ${ }^{2}$, H. Kiyama ${ }^{1}$ \\ ${ }^{1}$ Department of Anatomy, Asahikawa Medical College, Midorigaoka-Higashi, Asahikawa, Japan \\ ${ }^{2}$ Department of Ophthalmology, Asahikawa Medical College, Midorigaoka-Higashi, Asahikawa, Japan
}

\section{Abstract}

Aims/hypothesis. We investigated the association between vascular permeability and constitutive nitric oxide synthase in rats with diabetes for a short duration (2 weeks).

Methods. Retinal vascular permeability was evaluated in rats with diabetes induced by streptozotocin using vitreous fluorophotometry and a small animal adapter. We carried out in situ hybridization and semi-quantitative reverse transcription-polymerase chain reaction to study the expression of endogenous constitutive nitric oxide synthase mRNA in diabetic retinas. We also examined changes in the protein expression of constitutive nitric oxide synthase in diabetic retinas using immunohistochemistry and Western blotting.

Results. Retinal vascular permeability was significantly higher in diabetic rats (median, 1.09 arbitrary unit) compared with control rats (median, 0.69 arbitrary unit) $(p<0.05)$. The expression of both neuronal nitric oxide synthase (NOS) and endothelial ni- tric oxide synthase mRNA was higher in diabetic retinas than in the retinas of control rats as determined by in situ hybridization and reverse transcriptionpolymerase chain reaction. Immunohistochemistry and Western blotting also showed that neuronal nitric oxide synthase increased in diabetic retinas. The immunohistochemistry of endothelial nitric oxide synthase indicated that non-vessel tissues increased in diabetic retinas while retinal vessels weakened. Western blotting showed that the amount of endothelial nitric oxide synthase increased.

Conclusion/interpretation. These results suggest that increases in both constitutive NOSs (nNOS and eNOS) could be associated with retinal vascular permeability and that NOS is associated with clinical vascular dysfunction in the early stages of diabetes. [Diabetologia (2001) 44: 1043-1050]

Keywords Fluorophotometry, nitric oxide synthase, retinal vascular permeability, streptozotocin, in situ hybridization.
Received: 28 December 2000 and in revised form: 19 April 2001

Corresponding author: Fumihiko Mori, MD. PhD., Department of Ophthalmology, Asahikawa Medical College, Midorigaoka-Higashi 2-1-1-1, Asahikawa, Hokkaido 078-8510, Japan, E-mail: morinao@dion.ne.jp

Abbreviations: NOS, Nitric oxide synthase; nNOS, neuronal NOS; eNOS, endothelial NOS; NO, nitric oxide; ISH, in situ hybridization; RT-PCR, reverse transcription-polymerase chain reaction; GAPDH, glyceraldehyde 3-phosphate dehydrogenase; IHC, immunohistochemistry; BRB, blood-retinal barrier; VFP, vitreous fluorophotometry; VEGF, vascular endothelial growth factor; STZ, streptozotocin; INL, inner nuclear layer; GCL, ganglion cell layer; IR, immunoreactivity
Diabetes can result in retinopathy, which causes vision loss and blindness. Abnormalities of retinal vascular permeability precede the appearance of clinical retinopathy and could provide information about its pathogenesis. Increased retinal vascular permeability induced by retinal vascular disorders cause macular oedema [1], which decreases visual acuity and is difficult to cure clinically. Abnormal retinal vascular permeability caused by the breakdown of the blood-retinal barrier (BRB) was found in patients with diabetes and animals with experimentally induced diabetes using vitreous fluorophotometry (VFP) [2-5].

Vascular endothelial growth factor (VEGF) is a major vascular permeability factor increasing retinal 
vascular permeability when administered intravitreally [6-8]. The expression of VEGF or its receptor was up-regulated in association with increased vascular permeability in the retina of streptozotocin-induced diabetes (STZ) rats $[9,10]$. However, in the early stage of diabetes in rats, VEGF was not related to BRB breakdown [9].

A recent study suggested that VEGF increases nitric oxide (NO) production in human vascular endothelium [11]. The proliferation or relaxation of endothelial cells by VEGF stimulation was reduced by inhibitors of NO synthesis, such as N-monomethyl-Larginine, $\mathrm{N}$-nitro-L-arginine or $\mathrm{N}$-nitro-L-arginine methyl ester $[12,13]$. Calcium-dependent NO plays an important part in vascular permeability through cyclic guanosine monophosphate (GMP) [14]. The administration of NO increases retinal vascular permeability mediated through cyclic GMP increases [15].

We hypothesized that increased retinal vascular permeability is correlated with the activation of endogenous constitutive NO synthase (NOS), such as neuronal NOS (nNOS) and endothelial NOS (eNOS). Their activity depends on increased calcium levels in rats with early STZ-induced diabetes. We thus evaluated retinal vascular permeability and the expression of retinal constitutive NOS in diabetic rats and control rats using VFP, in situ hybridization (ISH), semi-quantitative reverse transcription-polymerase chain reaction (RT-PCR), immunohistochemistry (IHC), and Western blotting.

\section{Materials and methods}

Animal procedures. Male Wistar rats weighing 200-250 g were used for these experiments. All experiments involving animals were done in accordance with the principles of the Declaration of Helsinki. Diabetes in rats was induced with an intraperitoneal (i.p.) injection of $55 \mathrm{mg} / \mathrm{kg}$ of STZ (Sigma, St. Louis, Mo., USA) in $10 \mathrm{mmol} / \mathrm{l}$ citrate buffer ( $\mathrm{pH} \mathrm{4.5)}$ after a 12-h fast. All rats with blood glucose concentrations greater than $250 \mathrm{mg} / \mathrm{dl}$ after $24 \mathrm{~h}$ were considered to have developed diabetes. All rats were studied 2 weeks after the STZ injection.

Retinal vascular permeability. Diabetes was induced in five rats and five other rats served as control subjects. After 2 weeks, body weight, blood glucose and retinal vascular permeability were measured in the diabetic and control rats. VFP measurements were done using a Fluorotron Master (Ocumetrics, Mountainview, Calif., USA) with a small animal adapter to determine retinal vascular permeability [16]. Rats were anaesthetized with pentobarbital (i.p. $0.3 \mathrm{mg} / \mathrm{kg}$ ) $24 \mathrm{~h}$ before the VFP measurement and a polyvinyl catheter (inner diameter, $0.5 \mathrm{~mm}$ ) implanted into the right jugular vein as previously described [17-20]. The catheter was positioned subcutaneously along the rat's shoulder and the distal end was exposed at the back of the neck. Each catheter was flushed with $0.1 \mathrm{ml}$ of $1000 \mathrm{U}$ sodium heparin before and after placement. After baseline VFP measurements were obtained, fluorescein-Na (Alcon, Fort Worth, Tex., USA) ( $2 \mathrm{mg} / \mathrm{kg}$ body weight) was in- jected into the catheters. VFP was measured $30 \mathrm{~min}$ after the injection. Vitreous fluorescein (VF) concentrations were calculated from $3 \mathrm{~mm}$ in front of the retinal peak on the scale of the small animal adapter. Blood samples were collected 5 and $35 \mathrm{~min}$ after injection and centrifuged at $1500 \cdot \mathrm{g}$ for $10 \mathrm{~min}$. The samples then were centrifuged in an ultrafiltration membrane cone (Millipore, Tokyo, Japan) at $2000 \cdot \mathrm{g}$ for $15 \mathrm{~min}$. The plasma unbound fluorescein (PUF) was measured using the Fluorotron Master with a plasma adapter [16] and the PUF curve of the time course was obtained. Retinal vascular permeability was calculated from the VF level and the PUF curve. Retinal vascular permeability (arbitrary units) was calculated as the difference between the VF level at $30 \mathrm{~min}$ and the VF level at base line divided by the area under the PUF curve at 0 to $30 \mathrm{~min}$.

Section preparation. For section preparation, rats were killed using an overdose of pentobarbital and perfused with $4 \%$ paraformaldehyde/0.1 mol/l phosphate buffer (PB). Their eyes were enucleated and post-fixed in the same solution at $4{ }^{\circ} \mathrm{C}$ overnight. The eyes were then dehydrated and embedded in paraffin wax. Sections $7 \mu \mathrm{m}$ thick were mounted on 3-aminopropyltriethoxysilane-coated slides. The sections were stored under dry conditions until histologic analysis. The histologic results shown are representative of six control rats and six diabetic rats.

In situ hybridization. All in situ hybridization was done according to a previously reported method with minor changes [21]. For probe synthesis, rat cDNA fragments for nNOS (Genbank X59949, nt4112-4585, 473 base pairs [bp]) and eNOS (Genbank U18336, nt1-189, 189 bp) were isolated using RT-PCR. These fragments were subcloned into pBluescript II KS + vector (Stratagene, Calif., USA). These templates were linearized, and digoxigenin (DIG)-labelled cRNA probes were prepared by in vitro transcription using T7 or T3 RNA polymerase (Roche, Tokyo, Japan). Forty nanograms of the probes were used for each slide.

Pre-hybridization procedures and hybridization were done for about $12 \mathrm{~h}$ at $58^{\circ} \mathrm{C}$ for each probe. After hybridization, the slides were washed and equilibration in Buffer 1 (100 mmol/l TRIS-HCl, pH 7.5 and $150 \mathrm{mmol} / \mathrm{l} \mathrm{NaCl}$ ) for 5 min. Blocking was done with $20 \%$ sheep serum in Buffer 2 (Buffer 1 with $0.5 \%$ skimmed milk and $0.1 \%$ Tween 20 ) for $2 \mathrm{~h}$ at room temperature. The alkaline phosphatase-conjugated Fab fragments against DIG (diluted 1/2000 in $5 \%$ sheep serum/Buffer 2, Roche) were incubated overnight at $4{ }^{\circ} \mathrm{C}$. For colourization, the slides were washed $30 \mathrm{~min}$ three times in Buffer 1, equilibrated in Buffer 3 (100 mmol/l TRIS-HCl (pH 9.5), $100 \mathrm{mmol} / \mathrm{l} \mathrm{NaCl}$ and $50 \mathrm{mmol} / 1 \mathrm{MgCl}_{2}$ ) for $10 \mathrm{~min}$ and stained with NBT/BCIP stock solution (Roche) in Buffer 3 at room temperature for about $12 \mathrm{~h}$. The reaction was stopped with $10 \mathrm{mmol} / \mathrm{l}$ TRIS-HCl (pH7.6)/1 mmol/l EDTA, then the slides were mounted.

Semi-quantitative $R T-P C R$. The rats were killed as described previously. The eyes from the control rats and from the rats with diabetes for a duration of 2 weeks were immediately enucleated and the retinas were dissected from the scleral wall. The retinal total RNA was isolated using the AGPC method. The RNA extracted was quantitated by absorbance at 260 and $280 \mathrm{~nm}$. Then $3 \mu \mathrm{g}$ was used to synthesize cDNA by RT (SuperScript II, GIBCO BRL, Japan). PCR amplification was carried out with the following primers: CCTTCCGAAGCTTCTGGCAACAGC (sense) and TGGACTCAGATCTAAGGCGGTTGG (antisense) for nNOS (473 bp), TGCACCCTTCCGGGGATTCTGGCA (sense) and GGATCCCTGG- 


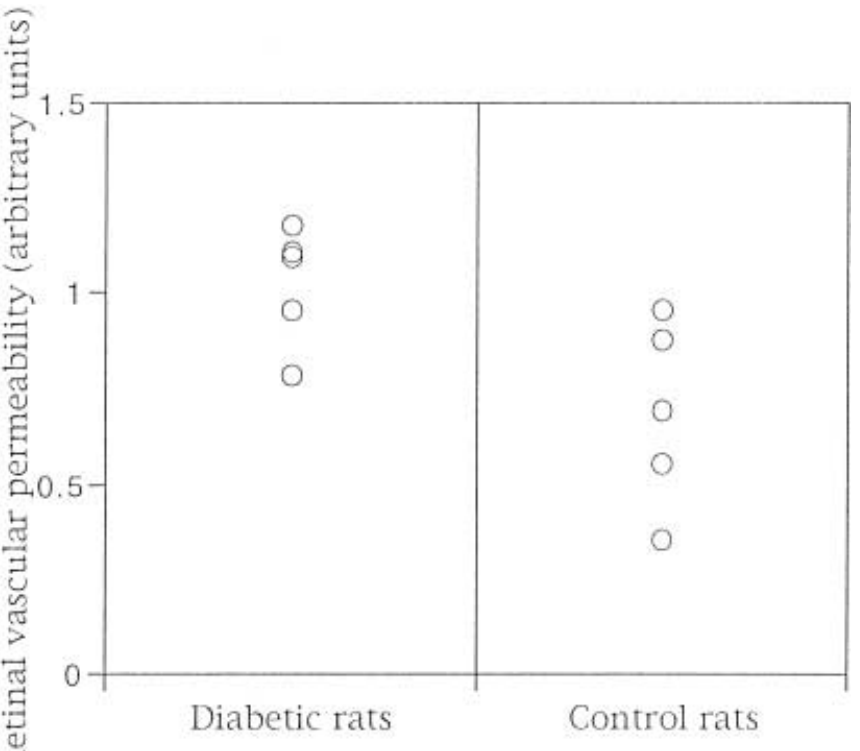

Fig.1. Retinal vascular permeability in diabetic rats $(n=5)$ and control rats $(n=5)$ using vitreous fluorophotometry

AAAAGGCGGTCAGG (antisense) for eNOS (189 bp), and AAGTTCAATGGCACAGTCAAGGCT (sense) and GAGGGTGCAGCGAACTTTATTGAT (antisense) for glyceraldehyde 3-phosphate dehydrogenase (GAPDH, 946 bp). The reaction was carried out for 23 to 30 cycles under the following conditions: denaturation, $95^{\circ} \mathrm{C}$ for $30 \mathrm{~s}$; annealing, $60^{\circ} \mathrm{C}$ for 45 $\mathrm{s}$; and extension, $72^{\circ} \mathrm{C}$ for $60 \mathrm{~s}$. The PCR products were electrophoresed through $2 \%$ agarose gel and photographed. The RT-PCR results shown represent those of three control rats and three diabetic rats.

Immunohistochemistry. The primary antibodies against eNOS and nNOS were purchased from Transduction Laboratories (Lexington, KY, USA). We carried out a specificity of these antibodies using preabsorbed antibody (biotin-conjugated goat anti-mouse Ig specific polyclonal antibody (multiple absorption), PharMingen, San Diego, Calif., USA) to confirm that immunoreactive staining did not occur. The sections were deparaffinized, rinsed in PBS, and treated with proteinase $\mathrm{K}$ $(10 \mu \mathrm{g} / \mathrm{ml})$ for $3 \mathrm{~min}$. The sections were blocked in $20 \%$ horse serum/PBS for $30 \mathrm{~min}$ at room temperature. These pretreated sections were incubated overnight at $4{ }^{\circ} \mathrm{C}$ with monoclonal antibodies, nNOS and eNOS (diluted $1 / 1000$ in PBS containing $0.5 \%$ Triton-X100/3\% BSA $/ 0.02 \%$ Na-Azide). The sections then were rinsed in PBS, incubated for $2 \mathrm{~h}$ at room temperature with horse biotinylated anti-mouse IgG (diluted 1/500 in $20 \%$ horse serum/PBS, Vector Laboratories, Calif., USA), rinsed again in PBS, and incubated in avidin/biotin-peroxidase complex (Vector Laboratories) for $1 \mathrm{~h}$ at room temperature. The sections then were rinsed in PBS and immersed in $0.05 \mathrm{~mol} / \mathrm{l}$ TRIS-HCl ( $\mathrm{pH}$ 7.6). Colourization was done in TRIS- $\mathrm{HCl}$ containing diaminobenzidine and hydrogen peroxide.

Retinal protein extraction and Western blotting. The retinal tissue was extracted as described previously. The total retinal protein was prepared according to a previously reported method [22]. The extracted tissue was solubilized in 3\% SDS buffer $(1 \mathrm{mmol} / \mathrm{l}$ orthovanadium, $0.1 \mu \mathrm{g} / \mathrm{ml}$ phenyl methyl sulfonyl fluoride and $0.19 \mu \mathrm{l} / \mathrm{ml}$ aprotinin), and boiled for $10 \mathrm{~min}$. The lysates were added to the same volume of $0.3 \mathrm{~mol} / \mathrm{l}$ sucrose, homogenized and centrifuged at 14000 rotations per minute for $15 \mathrm{~min}$ at $4{ }^{\circ} \mathrm{C}$. The lysates were stored at $-80^{\circ} \mathrm{C}$ until use.

For Western blotting, $50 \mu \mathrm{g}$ total protein in SDS sample buffer was applied to each lane. The samples were electrophoresed onto $10 \%$ SDS-polyacrylamide gels. After blotting, PVDF membranes were washed in TRIS-buffered saline containing $0.1 \%$ Tween-20 (TBST) and incubated with primary antibodies (diluted: $1 / 3000$ ) overnight at $4{ }^{\circ} \mathrm{C}$. The membrane was incubated with secondary antibody (sheep horseradish peroxidase linked anti-mouse Ig (Amersham, Tokyo, Japan), diluted $1 / 4000$ in $5 \%$ skim milk TBST) for $1 \mathrm{~h}$ at room temperature, and the ECL Western blot analysis system (Amersham) was used for detection. The Western blotting results shown represent four control rats and four diabetic rats. We also carried out an intensity analysis using NIH image.

Statistical analysis. Group comparisons were done using the unpaired Student's $t$-test with normal distributions and equal variance. Data was analysed using the Mann-Whitney rank sum test for populations with non-normal distributions or unequal variances. A $p$ value of less than 0.05 was considered to be statistically significant.

\section{Results}

Retinal vascular permeability. Significant differences were found in blood glucose concentrations (108.2 \pm 6.5 vs $351.4 \pm 72.6 \mathrm{mg} / \mathrm{dl})$ and body weight $(285.0 \pm$ 20.7 vs $235.0 \pm 22.7 \mathrm{~g}$ ) between the control and diabetic rats $(p<0.05)$. Retinal vascular permeability increased in the diabetic rats (median, 1.09 arbitrary unit; range, 0.78-1.17) compared with the control rats (median, 0.69 arbitrary unit; range, 0.35-0.95) $(p<0.05)$ (Fig. 1$)$.

Expression profile of $n N O S$ and eNOS $m R N A$ by in situ hybridization. We investigated nNOS and eNOS expression by ISH to determine if de novo synthesis occurred. In the control retinas, nNOS mRNA was expressed at a basal level in the inner nuclear layer (INL). Some strongly labelled cells were found in the innermost layer of the INL (Fig.2A, arrow). A few scattered positive cells were also detected in the ganglion cell layer (GCL), and were presumed to be displaced amacrine cells, as reported previously [23]. In the retinas of rats with diabetes of 2 weeks duration, nNOS expression increased in the INL and GCL cells (Fig. 2B). A weak positive signal from eNOS in the control retina was detected at the basal level in the INL and GCL cells (Fig. 2D). The eNOS expression also increased the number of expressing cells and the intensity of signal in the INL and GCL (Fig. 2E). The sense probes for both NOSs did not demonstrate any positive retinal staining (Fig.2C and F).

$R T-P C R$. To confirm the ISH results, we carried out semi-quantitative RT-PCR (Fig. 3). In the control retinas, the PCR product of nNOS was detectable but in 


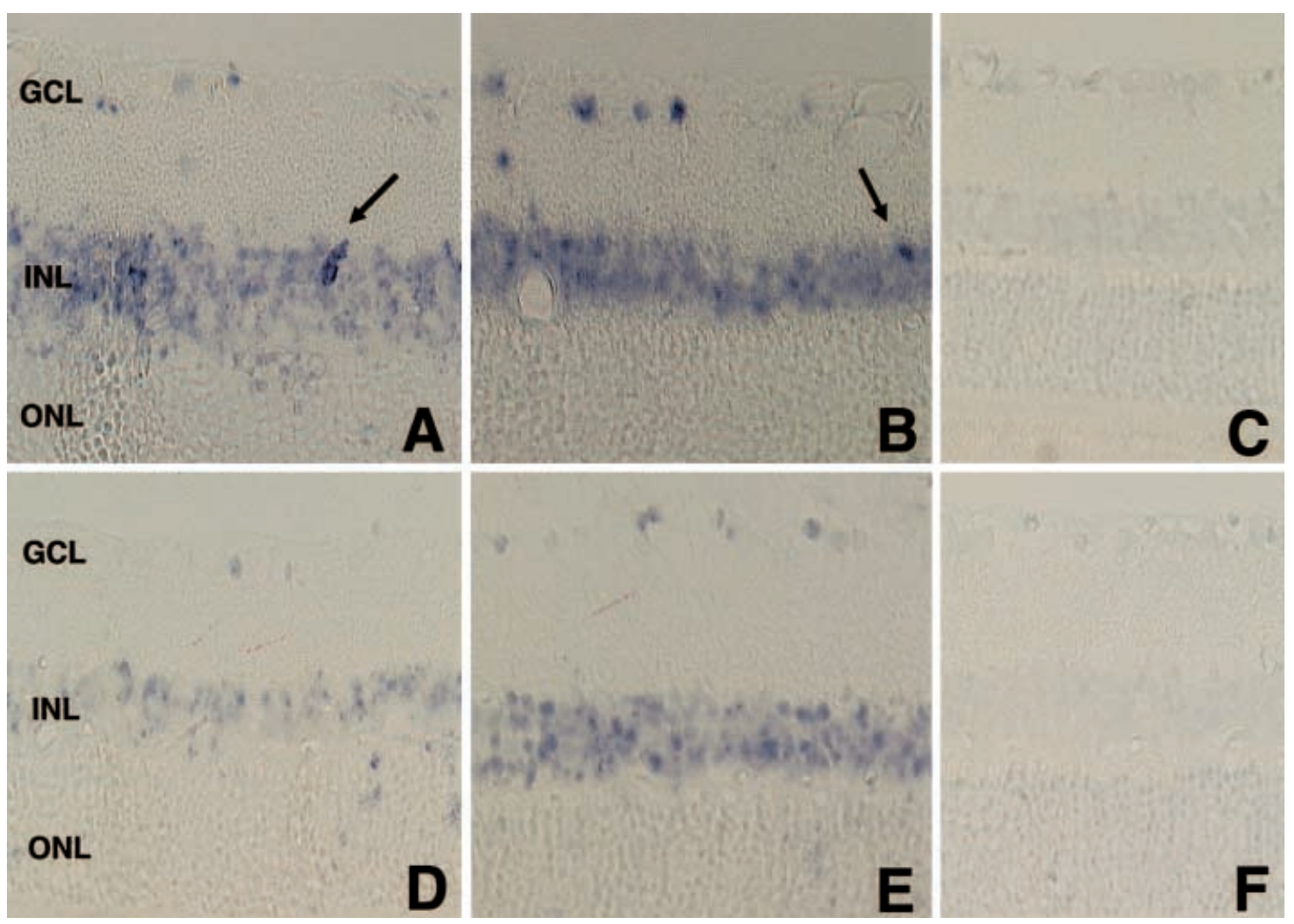

Fig. 2. The histologic mRNA expression of nNOS and eNOS. In situ hybridization (ISH) of the retina with $\mathrm{nNOS}(\mathbf{A}, \mathbf{B}, \mathbf{C})$ and eNOS $(\mathbf{D}, \mathbf{E}, \mathbf{F})$. The control retina $(\mathbf{A}, \mathbf{D})$ and retina from rats with diabetes $(\mathbf{B}, \mathbf{E})$. ISH by sense probe is done in specimens from rats with diabetes of 2 weeks duration $(\mathbf{C}, \mathbf{F})$. Arrow indicates the amacrine cells. GCL, ganglion cell layer; INL, inner nuclear layer; ONL, outer nuclear layer. Original magnification, $\times 200$

Fig.3. Semi-quantitative reverse transcription-polymerase chain reaction of nNOS and eNOS. The left lane of each figure (C) indicates the control retina. The right lane of each figure (D) indicates the retina from rats with diabetes. Amplification was done with 27 cycles for nNOS, 30 cycles for eNOS and 23 cycles for glyceraldehyde 3-phosphate dehydrogenase the diabetic retinas, the PCR products had undergone a great increase. A similar substantial increase of eNOS mRNA was observed in diabetic retinas. GAPDH, which served as an internal control, did not change in the PCR product in either control or diabetic rats. These results suggested that both NOS mRNA levels increased in the diabetic retina after STZ injection.

Expression profile of $n N O S$ and eNOS protein by IHC. Because the expression levels of nNOS and eNOS mRNA were different in the control and diabetic retinas, we evaluated protein expression using IHC. In the control retinas, nNOS immunoreactivity (IR) was detectable in the cells of the INL and GCL (Fig. 4A), although the number of positive cells was

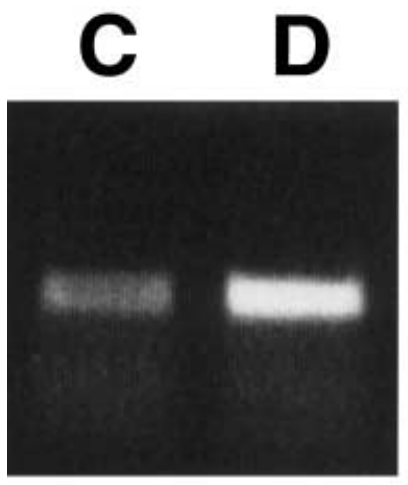

nNOS
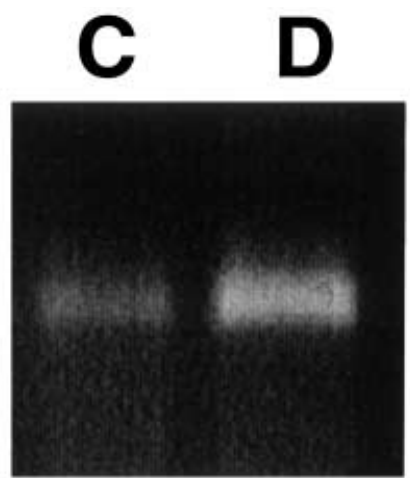

eNOS

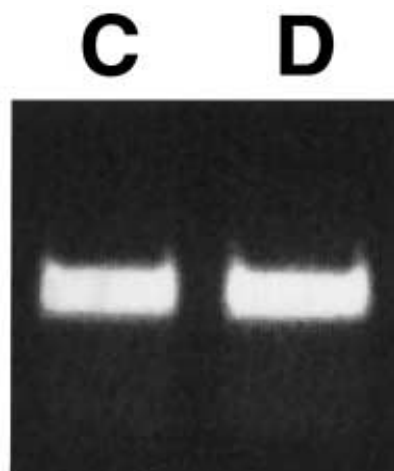

GAPDH 

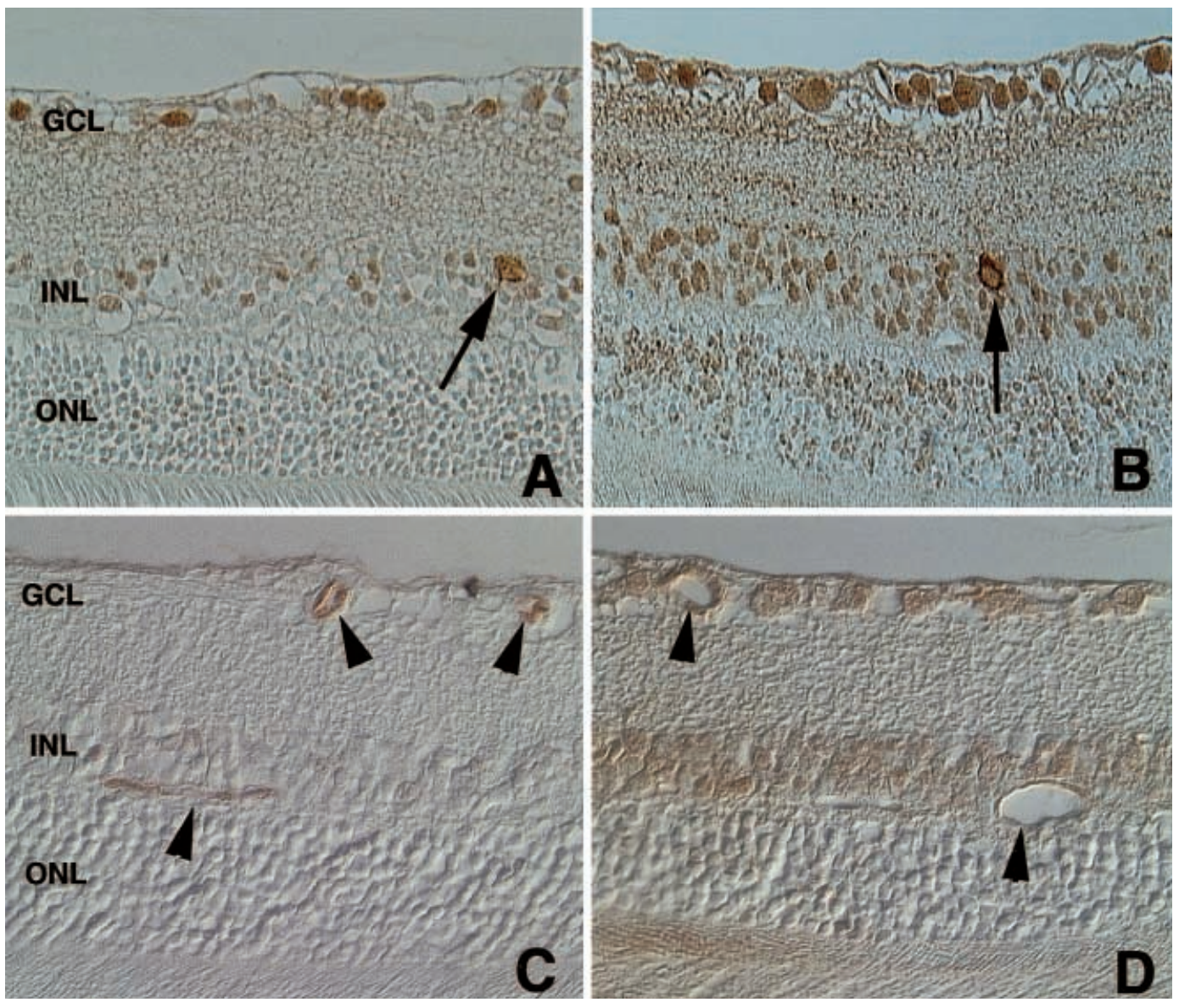

Fig.4. Immunohistochemistry (IHC) of nNOS and eNOS. IHC of the retina with nNOS $(\mathbf{A}, \mathbf{B})$ and eNOS $(\mathbf{C}, \mathbf{D})$. The control retina $(\mathbf{A}, \mathbf{C})$ and the diabetic retina $(\mathbf{B}, \mathbf{D})$. The arrows indicate the amacrine cells and arrowheads the vessels. GCL, ganglion cell layer; INL, inner nuclear layer; ONL, outer nuclear layer. Original magnification, $\times 200$

not large. As with ISH, strong immuno-positive cells were also observed at the innermost INL (Fig. 2A, arrow). In diabetic retinas, the expression of nNOS increased in the INL and GCL cells (Fig.4B). The nNOS IR in the cells located at the innermost layer of the INL was also stronger in the diabetic retina compared with control retinas. We observed nNOSIR neurites with varicosity, which were probably arborying fibres from cells located in the INL and/or the GCL, in the inner prexiform layer (IPL). In the case of eNOS IHC, the IR was detected very weakly in the INL cells in control retinas (Fig. 4C). However, strong IR was detected in the retinal vessels (Fig. 4C, arrowheads). In diabetic retinas, eNOS IR increased in the cells of INL and GCL (Fig. 4D). Vessel IR was relatively weak in diabetic retinas (Fig. 4D, arrowheads).

Quantitative protein level by Western blot. After finding the expression of both NOSs was altered in dia- betic retinas using IHC, we confirmed these increases by Western blotting (Fig. 5). Both nNOS and eNOS were detected at $155 \mathrm{kDa}$ and $140 \mathrm{kDa}$, respectively in the retinas from the control and the STZ-treated rats. After STZ injection, the expression levels of both NOSs increased. A densitometric analysis showed protein level of both NOSs were significantly increased in diabetic rats compared with the control rats.

\section{Discussion}

Abnormal retinal vascular permeability caused by BRB breakdown precedes the appearance of clinical diabetic retinopathy $[2,3]$. Our study shows that retinal vascular permeability, as measured by VFP, increased significantly in the STZ-induced diabetic rats compared with control rats. This finding agrees with the results of previous studies in which retinal vascular permeability also increased at an early stage of experimentally-induced diabetes [4, 5, 15, 24].

VEGF is a major vascular permeability factor $[6$, 7] and also increases retinal vascular permeability [8, 25]. The up-regulated expression of VEGF or its receptor was associated with increased vascular permeability in the retinas of STZ-induced diabetic rats [9, $10]$. However, in the early stages of diabetes, VEGF 


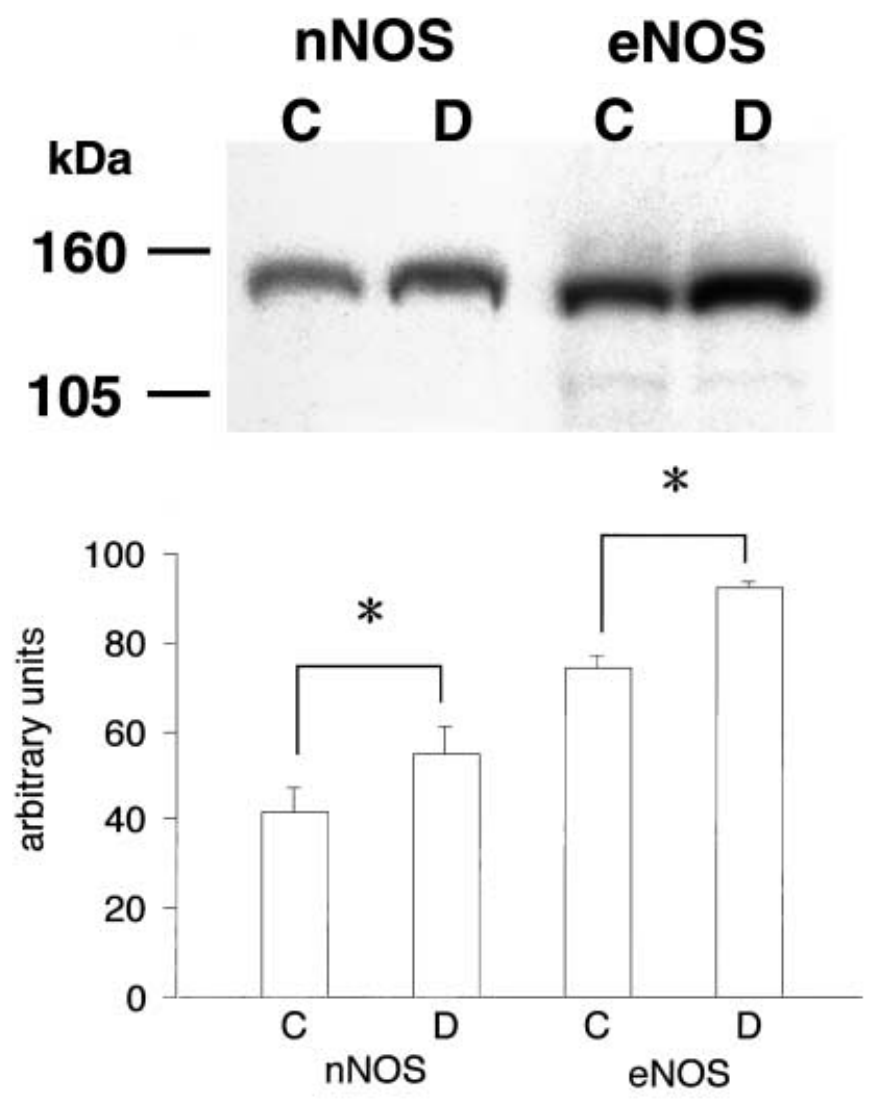

Fig. 5. Western blot analysis of nNOS and eNOS. (upper) The left lane of each figure $(\mathbf{C})$ indicates the control retina, the right lane (D) the diabetes retina. The left figure indicates protein size in $\mathrm{kDa}$ (lower). Relative amounts of $\mathrm{nNOS}$ and eNOS were shown by densitometry. Data are means \pm SD values from four control and four diabetic rats. A $p$ value of less than 0.05 was considered significant

is not up-regulated in the retina [9]. We found that VEGF expression in the diabetic retina 2 weeks after STZ injection, did not change (data not shown). Even though retinal vascular permeability precedes diabetic retinopathy $[2,3]$, the concentration of VEGF in the vitreous does not increase in the early stages of diabetic retinopathy [26] suggesting that another factor induces increased retinal vascular permeability in the retina soon after the onset of diabetes.

Recent studies suggest that VEGF induces vascular dysfunction by NO and that VEGF increases vascular permeability by NOS [11-13, 27, 28]. Intravitreous administration of $\mathrm{NO}$ caused increased retinal vascular permeability in a dose-dependent manner [15]. NO could, therefore, play a crucial role in retinal vascular permeability in diabetes.

Endogenous NOS in the retina in experimentally induced diabetes is not well understood. Using histologic and quantitative analyses, we demonstrated that the expression of endogenous NOS increased in the diabetic retina. The localization of nNOS mRNA in the normal retina agreed with previous re- ports [23]. In the diabetic retina, the mRNA signal increased in the INL and GCL cells. From their distribution and previous reports, positive cells in the INL were assumed to be bipolar, horizontal, and amacrine cells, and in the GCL, displaced amacrine cells [23, 29]. Although cell species that express nNOS need to be identified, our results suggest that various neural types of retinal cells, except photoreceptor cells, increased nNOS mRNA. Our IHC results showed the presence of nNOS IR in the INL and GCL cells but not in the plexiform layer of the control retina. These results partially disagreed with the results of earlier studies [23, 30-34] which indicated that nNOS IR was detected in the INL and GCL cells $[30,31]$. Some studies reported nNOS IR in the IPL $[23,31-34]$ but it was not observed [30]. The differences in these results might be because of the differences in using antibody or species. An undetected signal in our control IPL could be due to the low IR level because in diabetic retinas we observed strong IR in the IPL (Fig. 4B). For amacrine cells, the number of NADPH-diaphorase-positive cells has been shown to decrease after STZ injection and the intensity of staining not to have changed in diabetic samples compared with control samples [35]. We did not count the number of nNOS-positive cells but the nNOS IR of amacrine cells was stronger in the diabetic retinas. A histologic examination therefore revealed several discrepancies requiring further investigation. In the central nervous system, nNOS is up-regulated during hypoxia [36, 37]. Retinal blood flow has been shown to decrease in diabetic rats, the same model as in our study [17-20]. The tissue generally became, however, hypoxic under diabetic conditions [38]. Hypoxia of the retinal tissue, not the specific cell type, could increase nNOS expression in the diabetic rats.

Our study found weak eNOS at the basal level in INL and GCL cells in control retinas and stronger eNOS in the diabetic retina using both ISH and IHC. In the human hippocampus, eNOS was expressed in the pyramidal neurons and astroglia-like cells [39]. We found that the major reaction appeared in the INL cells, which contained neuronal and glial cell bodies. We assumed the reactive cells to be mainly Muller cells [40]. In the vascular endothelium, the retina became hypoxic under the diabetic conditions described previously. However eNOS remains controversial because its expression increases or decreases in various types of endothelium cells under hypoxic conditions [41-48]. Furthermore, in the eNOS IHC retinal vessel IR seems to be weak in the diabetic retina while non-vessel IR increases. In a monkey subarachnoid haemorrhage model, eNOS increased in the cerebral cortex but decreased in the cerebral artery [49], a phenomenon to our IHC results. One possible explanation for this discrepancy in the eNOS expression profile is that increased eNOS in non-vascular tissue could compensate for a decrease 
in the vessels. Although the amount of eNOS expression is altered in various tissues, the amount of eNOS increases in early diabetes, according to our quantitative results.

Both retinal constitutive NOS expression level and retinal vascular permeability increased in diabetic retinas. Exogenous NO increases the retinal vascular permeability in rats [15]. Retinal blood flow decreased because of the activation of protein kinase $\mathrm{C}$ or endothelin-1 induced by high glucose concentrations in diabetes $[19,20]$. Diabetic stress, including hypoxia, which is due to reduced retinal blood flow, could lead to increased free radical production in the retina and increase NOS. Thus, up-regulated constitutive NOS, which produces NO and is induced by diabetic stress, increases retinal vascular permeability in early diabetes. The retina, especially the INL, is composed of different types of cells, which vary in intricacy and in their forms of contact with other tissue. NO is produced by NOS from non-vascular tissue and has diffusible influences on retinal vessel and other tissue [50]. However, permeability could increase initially for some reason yet to be found, with a subsequent stimulation of the retinal tissue and expression of constitutive NOS.

In conclusion, increases in retinal vascular permeability can be found in the retina even in the early stages of diabetes. Constitutive NOS is also found to increase by histologic and quantitative analyses. Increased retinal vascular permeability could be associated with NOS up-regulation in the early stages of diabetic retinas suggesting that NOS is related to clinical vascular dysfunction in the early stages of diabetes. Abnormal production of NO could contribute to the development of diabetic retinopathy.

Acknowledgements. This study was supported by Grant-inaid for General Scientific Research C70125417.

\section{References}

1. Aiello LP, Cavallerano J, Bursell SE (1996) Diabetic eye disease. Endocrinol Metab Clin North Am 25: 271-291

2. Yoshida A, Ishiko S, Kojima M, Ogasawara H (1993) Permeability of the blood-ocular barrier in adolescent and adult diabetic patients. Br J Ophthalmol 77: 158-161

3. Cunha-Vaz JG, Gray JR, Zeimer RC, Mota MC, Ishimoto BM, Leite E (1985) Characterization of the early stages of diabetic retinopathy by vitreous fluorophotometry. Diabetes 34: 53-59

4. Jones CW, Cunha-Vaz J, Zweig KO, Stein M (1979) Kinetic vitreous fluorophotometry in experimental diabetes. Arch Ophthalmol 97: 1941-1943

5. Vine AK, Kisly AM, Betz AL, Howatt WF (1984) Vitreous fluorophotometry in rats with streptozocin-induced diabetes. Arch Ophthalmol 102: 1083-1085

6. Senger DR, Galli SJ, Dvorak AM, Perruzzi CA, Harvey VS, Dvorak HF (1983) Tumor cells secrete a vascular permeability factor that promotes accumulation of ascites fluid. Science 219: 983-985
7. Keck PJ, Hauser SD, Krivi G et al. (1989) Vascular permeability factor, an endothelial cell mitogen related to PDGF. Science 246: 1309-1312

8. Aiello LP, Bursell SE, Clermont A et al. (1997) Vascular endothelial growth factor-induced retinal permeability is mediated by protein kinase $\mathrm{C}$ in vivo and suppressed by an orally effective beta-isoform-selective inhibitor. Diabetes 46: $1473-1480$

9. Murata T, Nakagawa K, Khalil A, Ishibashi T, Inomata H, Sueishi K (1996) The relation between expression of vascular endothelial growth factor and breakdown of the bloodretinal barrier in diabetic rat retinas. Lab Invest 74: $819-825$

10. Hammes HP, Lin J, Bretzel RG, Brownlee M, Breier G (1998) Upregulation of the vascular endothelial growth factor/vascular endothelial growth factor receptor system in experimental background diabetic retinopathy of the rat. Diabetes 47: 401-406

11. van der Zee R, Murohara T, Luo Z et al. (1997) Vascular endothelial growth factor/vascular permeability factor augments nitric oxide release from quiescent rabbit and human vascular endothelium. Circulation 95: 1030-1037

12. Morbidelli L, Chang CH, Douglas JG, Granger HJ, Ledda F, Ziche M (1996) Nitric oxide mediates mitogenic effect of VEGF on coronary venular endothelium. Am J Physiol 270: H411-H415

13. Ku DD, Zaleski JK, Liu S, Brock TA (1993) Vascular endothelial growth factor induces EDRF-dependent relaxation in coronary arteries. Am J Physiol 265: H586-H592

14. He P, Liu B, Curry FE (1997) Effect of nitric oxide synthase inhibitors on endothelial $[\mathrm{Ca} 2+] \mathrm{i}$ and microvessel permeability. Am J Physiol 272: H176-H185

15. Mori F, Allen C, Koya D et al. (1997) The effect of nitric oxide of retinal hemodynamics in nondiabetic and diabetic rats. Diabetes [Suppl]

16. Ishiko S, Yoshida A, Kitaya N et al. (1996) Fluorophotometry with a small animal adapter. Jpn J Ophthalmol 40: 310-316

17. Bursell SE, Clermont AC, Shiba T, King GL (1992) Evaluating retinal circulation using video fluorescein angiography in control and diabetic rats. Curr Eye Res 11: 287-295

18. Bursell SE, Clermont AC, Oren B, King GL (1995) The in vivo effect of endothelins on retinal circulation in nondiabetic and diabetic rats. Invest Ophthalmol Vis Sci 36: 596-607

19. Takagi C, Bursell SE, Lin YW et al. (1996) Regulation of retinal hemodynamics in diabetic rats by increased expression and action of endothelin-1. Invest Ophthalmol Vis Sci 37: 2504-2518

20. Takagi C, King GL, Takagi H, Lin YW, Clermont AC, Bursell SE (1996) Endothelin-1 action via endothelin receptors is a primary mechanism modulating retinal circulatory response to hyperoxia. Invest Ophthalmol Vis Sci 37: 2099-2109

21. Takeda M, Kato H, Takamiya A, Yoshida A, Kiyama H (2000) Injury-specific expression of activating transcription factor-3 in retinal ganglion cells and its colocalized expression with phosphorylated c-Jun. Invest Ophthalmol Vis Sci 41: 2412-2421

22. Kenney AM, Kocsis JD (1997) Timing of c-jun protein induction in lumbar dorsal root ganglia after sciatic nerve transection varies with lesion distance. Brain Res 751:90-95

23. Shin DH, Lee HY, Kim HJ et al. (1999) In situ localization of neuronal nitric oxide synthase (nNOS) mRNA in the rat retina. Neurosci Lett 270: 53-55

24. Tso MO, Cunha-Vaz JG, Shih CY, Jones CW (1980) Clinicopathologic study of blood-retinal barrier in experimental diabetes mellitus. Arch Ophthalmol 98: 2032-2040 
25. Tolentino MJ, Miller JW, Gragoudas ES et al. (1996) Intravitreous injections of vascular endothelial growth factor produce retinal ischemia and microangiopathy in an adult primate. Ophthalmology 103: 1820-1828

26. Aiello LP, Avery RL, Arrigg PG et al. (1994) Vascular endothelial growth factor in ocular fluid of patients with diabetic retinopathy and other retinal disorders. N Engl J Med 331: 1480-1487

27. Ziche M, Morbidelli L, Choudhuri R et al. (1997) Nitric oxide synthase lies downstream from vascular endothelial growth factor-induced but not basic fibroblast growth factor-induced angiogenesis. J Clin Invest 99: 2625-2634

28. Tilton RG, Kawamura T, Chang KC et al. (1997) Vascular dysfunction induced by elevated glucose levels in rats is mediated by vascular endothelial growth factor. J Clin Invest 99: 2192-2202

29. Ahmad I, Leinders-Zufall T, Kocsis JD, Shepherd GM, Zufall F, Barnstable CJ (1994) Retinal ganglion cells express a cGMP-gated cation conductance activatable by nitric oxide donors. Neuron 12: 155-165

30. Perez MT, Larsson B, Alm P, Andersson KE, Ehinger B (1995) Localisation of neuronal nitric oxide synthase-immunoreactivity in rat and rabbit retinas. Exp Brain Res 104: 207-217

31. Yamamoto R, Bredt DS, Snyder SH, Stone RA (1993) The localization of nitric oxide synthase in the rat eye and related cranial ganglia. Neuroscience 54: 189-200

32. Lopez-Costa JJ, Goldstein J, Saavedra JP (1997) Neuronal and macrophagic nitric oxide synthase isoforms distribution in normal rat retina. Neurosci Lett 232: 155-158

33. Liepe BA, Stone C, Koistinaho J, Copenhagen DR (1994) Nitric oxide synthase in Muller cells and neurons of salamander and fish retina. J Neurosci 14: 7641-7654

34. Meyer P, Champion C, Schlotzer-Schrehardt U, Flammer J, Haefliger IO (1999) Localization of nitric oxide synthase isoforms in porcine ocular tissues. Curr Eye Res 18: 375-380

35. Roufail E, Soulis T, Boel E, Cooper ME, Rees S (1998) Depletion of nitric oxide synthase-containing neurons in the diabetic retina: reversal by aminoguanidine. Diabetologia 41: $1419-1425$

36. Matsuoka Y, Kitamura Y, Tooyama I, Kimura H, Taniguchi T (1997) In vivo hypoxia-induced neuronal damage with an enhancement of neuronal nitric oxide synthase immunoreactivity in hippocampus. Exp Neurol 146: 57-66

37. Dawson VL, Kizushi VM, Huang PL, Snyder SH, Dawson TM (1996) Resistance to neurotoxicity in cortical cultures from neuronal nitric oxide synthase-deficient mice. J Neurosci 16: $2479-2487$
38. Williamson JR, Chang K, Frangos M et al. (1993) Hyperglycemic pseudohypoxia and diabetic complications. Diabetes 42: 801-813

39. Doyle CA, Slater P (1997) Localization of neuronal and endothelial nitric oxide synthase isoforms in human hippocampus. Neuroscience 76: 387-395

40. Haverkamp S, Kolb H, Cuenca N (1999) Endothelial nitric oxide synthase (eNOS) is localized to Muller cells in all vertebrate retinas. Vision Res 39: 2299-2303

41. Arnet UA, McMillan A, Dinerman JL, Ballermann B, Lowenstein CJ (1996) Regulation of endothelial nitric-oxide synthase during hypoxia. J Biol Chem 271: 15069-15073

42. Le Cras TD, Xue C, Rengasamy A, Johns RA (1996) Chronic hypoxia upregulates endothelial and inducible NO synthase gene and protein expression in rat lung. Am J Physiol 270: L164-L170

43. Xu XP, Pollock JS, Tanner MA, Myers PR (1995) Hypoxia activate s nitric oxide synthase and stimulates nitric oxide production in porcine coronary resistance arteriolar endothelial cells. Cardiovasc Res 30: 841-847

44. Laufs U, Fata VL, Liao JK (1997) Inhibition of 3-hydroxy3-methylglutaryl (HMG)-CoA reductase blocks hypoxiamediated down-regulation of endothelial nitric oxide synthase. J Biol Chem 272: 31725-31729

45. Adnot S, Raffestin B, Eddahibi S, Braquet P, Chabrier PE (1991) Loss of endothelium-dependent relaxant activity in the pulmonary circulation of rats exposed to chronic hypoxia. J Clin Invest 87: 155-162

46. Liao JK, Zulueta JJ, Yu FS, Peng HB, Cote CG, Hassoun PM (1995) Regulation of bovine endothelial constitutive nitric oxide synthase by oxygen. J Clin Invest 96: 2661-2666

47. McQuillan LP, Leung GK, Marsden PA, Kostyk SK, Kourembanas S (1994) Hypoxia inhibits expression of eNOS via transcriptional and posttranscriptional mechanisms [published errata appear in Am J Physiol 1995 Feb: 268:section $\mathrm{H}$ following table of contents and 1995 Jun: 268:section $\mathrm{H}$ following table of contents]. Am J Physiol 267: H1921-H1927

48. Ziesche R, Petkov V, Williams J et al. (1996) Lipopolysaccharide and interleukin 1 augment the effects of hypoxia and inflammation in human pulmonary arterial tissue. Proc Natl Acad Sci U S A 93: 12478-12483

49. Hino A, Tokuyama Y, Weir B et al. (1996) Changes in endothelial nitric oxide synthase mRNA during vasospasm after subarachnoid hemorrhage in monkeys. Neurosurgery 39: 562-567 discussion 567-568

50. Ignarro LJ (1990) Nitric oxide. A novel signal transduction mechanism for transcellular communication. Hypertension 16: $477-83$ 